\title{
Simple Analytics of the Money Supply Process and Monetary Control
}

\section{DANIEL L. THORNTON}

N OCTOBER 6, 1979, the Federal Reserve adopted a new procedure for implementing monetary policy that would place more emphasis on controlling the money supply and less on controlling the level of the federal funds rate. This procedure has been implemented by establishing an intermediate target for nonborrowed reserves. ${ }^{1}$ While the Federal Reserve has succeeded in slowing the rate of growth in the basic monetary aggregate (MI) since adopting the new procedure, it has failed to smooth the erratic short-run movements in Ml.

Analysts have suggested a number of changes to the Federal Reserve's operating procedure to achieve more stable short-run monetary growth. Among the most frequently cited proposals are: adopting a monetary base target, tying the discount rate to a market interest rate and adopting a system of contemporaneous reserve accounting (CRA). ${ }^{2}$ The Board of Gov-

\footnotetext{
IFor a fiscussion of the new operating procedures, see Fred J. Levin and Paul Meek, "Implemerting the New Operating Procedures: The View from the Trading Desk," New Monetary Control Procedures, Volume I, Fecteral heserve Staf Study (Board of Governors of the Federal Reserve System, February 1981); Stephen Axilrod and David E. Lindsey, "Federal Reserve System Implenentation of Monetary Policy: Analyteal Foundations of the New Approach," American Eoonomir Review (May 1981), pp. 246-52; and $\mathrm{R}$. Alton Gibert and Michael $\mathrm{E}$. Trebing, "Fhe FOMC in 1980. A Year of Reserve Targeting," this Review (Anyust/ September 1981 j, pp. $2-22$.

There have been a number of suggestions for these reforms. For example, Economic Report of the President (1982), Anatol B. Balbach, "How Controllable is Money Growth?" this Review (April 1981) pp. 3-12 James M. Johanes and Robert H. Rasche, "Predicting the Money Multipher:" Journal of Monetary Economics
}

ernors is now committed to implementing the last of these recommendations. ${ }^{3}$

The purpose of this paper is to analyze the effects of adopting each of these proposals. Since each of these recommendations, in some way, are linked to the others, the analysis will proceed serially, beginning with the effects of base targeting and ending with the effects of CRA. These proposed reforms are analyzed within the context of a simple linear stochastic model of the money stock. ${ }^{4}$

\section{A MODE OF The MONEY STOCK}

The model used here is complete enough to provide useful insights into the effects of each of these proposals, yet simple enough to be readily understood. The reader need not follow each step in the development of the model in order to understand its implications. All

(July 1979), pp. 30J-26, and "Can the Reserves Approach to Monetary Control Really Work?" Journal of Money, Credit and Banking (August 1981), pp. 298-313; Willan Poole, "Federal Reserve Operating Procedures: A Survey and Evaluation of the Historical Record Since October 1979, presented at the Conference on Carrent Issues in the Conduct of Monetary Policy, Ameriean Enterprise Institute (Febmary 1982).

The Federal Reserve will implement Chat on Ifobury $2,1984$.

The molel is a more comphicated version of hinear stockastic models recently considered by Poole and LeRoy. See Poole, "Federal Reserve Operating Procedures: A Survey and tyaluation of the Historical Recorn Since October 1979 " and Stepher F. Lekoy. "Monetary Control Under Lagged Reserve Aconzting "Southern Economic Journal (October 1979), pp. $460-70$. 
Table 1

\section{A Simple Linear Model of the Money Stock}

Equations:

\section{Money Supply Equations}

$\mathrm{M}_{\mathrm{P}} \mathrm{O} \mathrm{D}_{\mathrm{t}}, \mathrm{c}$

$\mathrm{B}, \mathrm{AR}+\mathrm{C}_{1} \mathrm{En}$

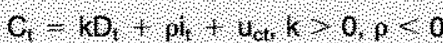

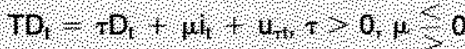

$\mathrm{EA}, \mathrm{eD}_{\mathrm{t}}$, o,, t vat $\mathrm{e}, 0,0,40$

$\mathrm{AP}, \mathrm{rO}, \mathrm{TO})$

$\mathrm{BH}+\mathrm{En}_{\mathrm{t}}=\mathrm{NBH},+\mathrm{BR}$

$\mathrm{BR}_{\mathrm{t}}=\mathrm{a}(\mathrm{id},+1)+\mathrm{u}_{\mathrm{b}, \mathrm{O}}<0$

\section{Money Demand Equations}

$\mathrm{M}_{\mathrm{d}}^{\mathrm{d}}=\mathrm{BY}, \mathrm{Al}, \mathrm{u}_{\mathrm{n}, \mathrm{B}} \mathrm{B}>0, \mathrm{~N}=0$

\section{Warket Equilibrium Condition}

$M_{t}=M_{t}^{d} M_{t}$
Definitions of Variables

$\mathrm{M}^{\mathrm{S}}$, the supply of nominal noney, composed of checkable deposits and currency

D checkable deposits of depository institutions

C) the currency component of money

B Y the nonetary base

PA required reserves of depository institutions

TD tine and savings deposits of depository institutions

ER oxcess reserves of depository institutions

$\mathrm{NBA}$ nonborrowed reserves: total reseves of depository institutions less depository institutions borrowing from the Federal fieserve

BR depository institutions borrowing rom the federal Reserve

10 the nominal market interest rate

10 the discount rate

$Y$ nominal GNP

$M^{\alpha}$ the demand for nominal money

$\mathrm{M}$ the equilbrium nominal money stock

$\mathrm{U}_{\mathrm{c}} \mathrm{U}_{\mathrm{f}}$, random variables with zero means and constant $\mathrm{U}_{\mathrm{et}}, \mathrm{U}_{\mathrm{b}}$, variances.

$\mathrm{U}_{\mathrm{nt}}$

\section{Descriptions of Equations.}

The first two equations are the definitions of money stock and the monetary base, respectively the next three equations are parametric equations relating currency held by the nonbank $\mathrm{ptb}$ lic, time deposits and excess resenves to checkable deposits and the market interest rate These equations also contain random components that represent both purely stochastic elements and the effects of omitted variables the sixth is an identity relating requited resenves to total deposits and the seventh is an equilibrum condition requiting the demand for reserves to equal the supply of reserves, The eighth equation makes depository institu tions demand tor borrowed teserves a function of the spread between the Federal Reserve discount rate and the market in terest rate, and the randon error The node is completed by including a simple demand for money equation and a noney equilibitum condition The denand for nominal money is assumed to depend on nominal income and the market interest rate. 2 Infation and hence, expectations of intlation are ignored

This borrowing equation ditters tom the usual one, The usual borrowing equation would relate borrowing to bank depostls parametrically, say

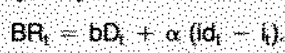

This practice is not adopted here for the following reasons. Firs, there is ittle theoretical fustification for parametrically relating borrowing to the level of deposits. Second this practice results in including the b-term in the multiplier, This gives the erroneous impression that the link between money and the base will change with changes in $b$ evenunder base targeting but this is not the case this point will be made olear later in the paper It is true that there would be some frictional tevel of borrowing even if id, = Thus it might be appropriate to include a constant term in equation 8 .

Third it is possible to obtan a nonborro wed resenve multiplier by completely ignoring equation 2 when the borrowing equation is written in the above form This encourages one to ignore the fact that nonborrowed reserves are finked to money only via their link to the base or total reserves.

${ }^{2}$ That is we follow common practice in assuming the absence of a money lluston' on the part of money holders. 
of the results presented are derived in the appendix. Nevertheless, the complete model along with a description of the equations and variables is presented in table 1 for the reader's convenience. Wherever possible, the analysis is presented graphically.

The model initially assumes CRA. This assumption will be changed later to analyze the implications of lagged reserve accounting (LRA) for short-run monetary control and to analyze the effects of the Board's proposal for CRA. Initially, the deterministic form of the model is considered. This is achieved by taking the expected value of the endogenous variables (the expected value is denoted with a hat, e.g., $\mathrm{E}(\mathrm{X})=\hat{\mathrm{X}}$ ). The full model is taken up in the final section, which deals with the variance of money and interest rates under CRA and LRA.

The model requires that three variables be exogenous. Two of the exogenous variables are the discount rate $\left(\mathrm{id}_{\mathrm{t}}\right)$ and nominal income $\left(\mathrm{Y}_{\mathrm{t}}\right)$. The remaining exogenous variable is determined by the operating procedure. If the Federal Reserve chooses to target on the market interest rate $\left(\mathbf{i}_{t}\right)$, it would be treated as exogenous; in this case, the monetary base $\left(B_{t}\right)$ and nonborrowed reserves $\left(\mathrm{NBR}_{\mathrm{t}}\right)$ would change to whatever levels are necessary to achieve the interest rate target. If the Federal Reserve targets on nonborrowed reserves, the monetary base and the interest rate would move endogenously to achieve levels consistent with the nonborrowed reserve target. The same would be true of the interest rate and nonborrowed reserves if the Federal Reserve chose a monetary base target.

Control of the money stock through each of these targets can be analyzed by evaluating the expressions for the expected value of the equilibrium money stock obtained by treating each of these variables as exogenous. (The Federal Reserve must forecast the level of income $Y_{t}$ in order to control the money stock. Thus, the forecasted value $\hat{Y}_{t}$ replaces $Y_{t}$ in the model. ${ }^{5}$ The expected value of the equations for the equilibrium money stock under monetary base, nonborrowed reserve and interest rate targeting, respectively, are:

(1) $\hat{M}_{t}=\frac{\lambda}{\frac{(\lambda-\rho)(r(1+\tau)+e+k)}{1+k}+(r \mu+\delta+\rho)} B_{t}$

\footnotetext{
specifically, we assume that $Y_{t}=\hat{Y}_{t}+\varepsilon_{t}$, where $\mathbf{E}\left(\varepsilon_{t}\right)=0$. Thas, $\mathbf{E}\left(\mathrm{Y}_{t}\right)=\hat{\mathbf{Y}}_{\mathrm{L}}, \mathrm{i}$. $\mathrm{e}_{\text {. }}$, the Federal Reserve correctly forecasts nominal income on average. This forecast introduces another source of error into the model which is ignored in this paper for convenience; however, this does not affect the qualitative conclusions. The Federal Reserve has to forecast the parameters of the model as well. This problem is ustally ignored.
}

$$
+\frac{\beta\left[(\mathrm{r} \mu+\delta+\rho)-\frac{\rho(\mathrm{r}(1+\tau)+e+k)}{1+\mathrm{k}}\right]}{\frac{(\lambda-\rho)(\mathrm{r}(1+\tau)+e+k)}{1+k}+(\mathrm{r} \mu+\delta+\rho)} \hat{\mathrm{Y}}_{\mathrm{t}}
$$

(2) $\hat{M}_{t}=\frac{\lambda}{\frac{(\lambda-\rho)(r(1+\tau)+e)}{1+k}+(r \mu+\delta+\alpha)}$ NBR $_{t}$

$$
\begin{aligned}
& +\frac{\beta\left[(\mathrm{r} \mu+\delta+\alpha)-\frac{\rho(\mathrm{r}(1+\tau)+e)}{1+k}\right]}{\frac{(\lambda-\rho)(\mathrm{r}(1+\tau)+e)}{1+k}+(\mathrm{r} \mu+\delta+\alpha)} \hat{\mathrm{Y}}_{\mathrm{t}} \\
& +\frac{\alpha \lambda}{\frac{(\lambda-\rho)(\mathrm{r}(1+\tau)+\mathrm{e})}{1+\mathrm{k}}+(\mathrm{r} \mu+\delta+\alpha)} \mathrm{id}_{\mathrm{t}}
\end{aligned}
$$

(3) $\hat{\mathbf{M}}_{\mathbf{t}}=\beta \hat{\mathbf{Y}}_{\mathrm{q}}+\lambda \mathbf{i}_{\mathrm{t}}$

The expected value of the equilibrium money stock under interest rate targeting (equation 3) is simply the demand for money. This reflects the well-known fact that the quantity of money is completely demand. determined if the Federal Reserve chooses an interest rate target. ${ }^{6}$

While these equations appear somewhat complicated, they merely represent expressions for the expected value of the equilibrium money stock, represented graphically by $\hat{\mathbf{M}}^{*}$ in figure 1 . For example, both the base and income appear in the equilibrium equation 1, because the money supply is conditional on the level of the base under base targeting and the demand for money is conditional on the income level. This is illustrated in figure la. Therefore, the equilibrium money stock depends both on the level of income and the base under a monetary base target.

The discount rate appears in the money stock equation when nonborrowed reserves are exogenous, but not when the monetary base is exogenous. The reason for this is simple. Changes in the discount rate alter the spread between it and the market interest rate and,

\footnotetext{
${ }^{6}$ In this case, the money supply curve would be perfectly horizontal, as the Federal Reserve simply accommodated the public's demand for money at some nominal rate. Of course, it is well-known and widely accepted that the Federal Reserve cannot "peg" the nominal rate in an inflationary environment without continnously accelerating the growth rate of money. See Milton Friedman, "The Role of Monetary Policy," American Economic Review (March 1968), pp. 1-17. More recently, however, McCallum has shown that the price level is deteminant if the Federal Reserve smoothes rather than pegs interest rates. See Bennett $T$. McCallum, "Price Level Determinancy with an Interest Rate Policy Rule and Rational Expectations," Journal of Monetary Economics (November 1981), pp. 319-29.
} 


\section{Figure 1}

\section{Equilibrium Money Stock Under Base and Monborrowed Reserve Targefing}

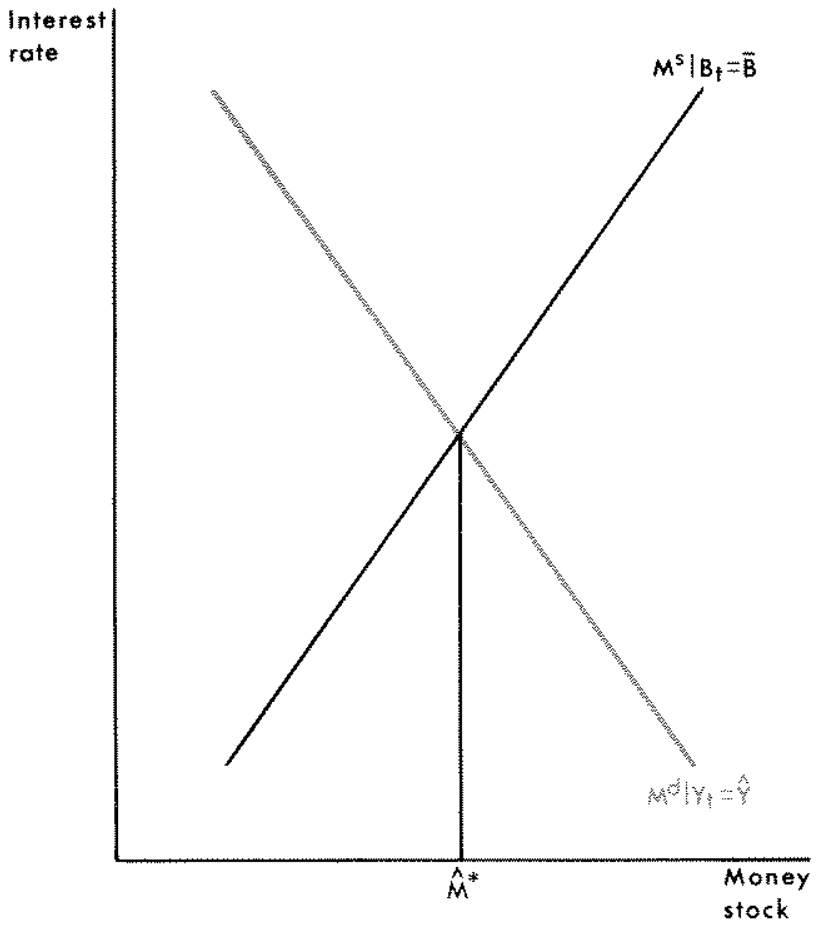

(a)

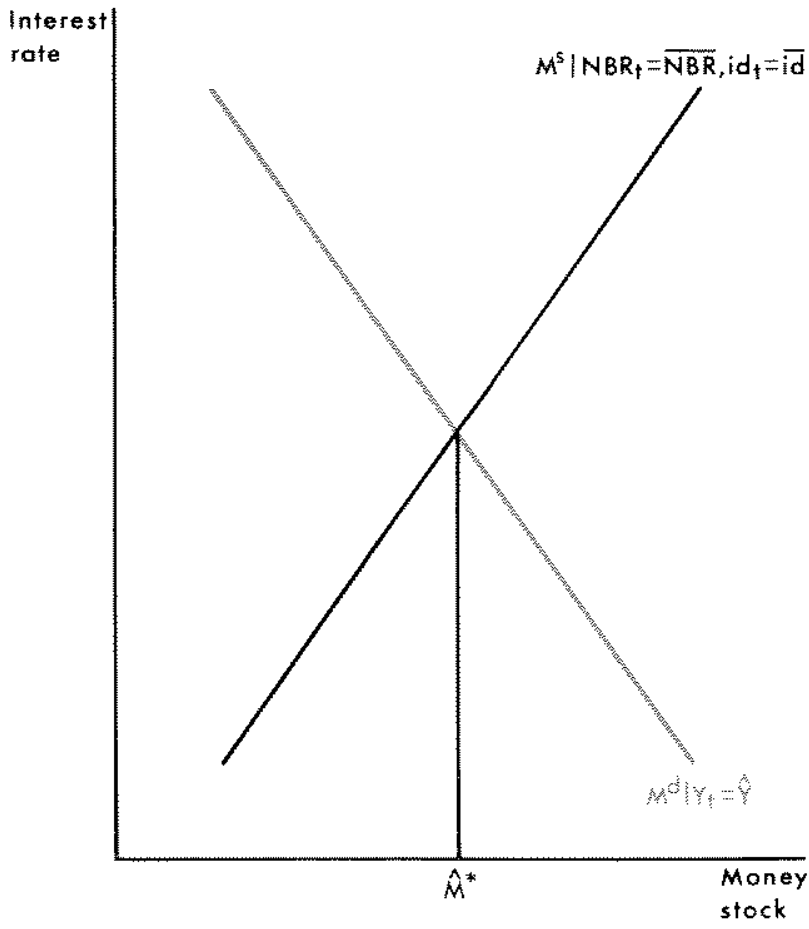

(b) thus, the level of bank borrowing. "If the monetary base were the control variable, changes in borrowings would be offset through open market operations in order to maintain the base at its target level. Changes in the discount rate would have no effect on the equilibrium money stock under monetary base targeting. Thus, the discount rate does not appear as an exogenous variable in equation 1.

This is not the case for nonborrowed reserve targeting. Changes in the discount rate would produce changes in depository institutions' borrowing, the monetary base and the money supply unless the Federal Reserve simultaneously changes its target level of nonborrowed reserves. ${ }^{8}$ Thus, the money

"If there were a significant "announcement effect" of a discount rate change on market interest rates, there would be an endogenous movement in the money stock even under base targeting. For more details on the relationship between the discount rate and market interest rates, see Daniel L. Thornton, "The Discount Rate and Market Interest Rates: What's the Connection?" this Review (June/July 1982), pp. 3-14.

${ }^{3}$ If the Federal Reserve changed its nonborrowed reserve target in light of these changes, it would, ipso facto, be targeting on the base supply schedule is conditional on both nonborrowed reserves and the discount rate under nonborrowed reserve targeting, as illustrated in figure $1 \mathrm{~b}$.

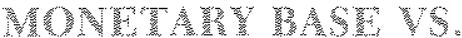

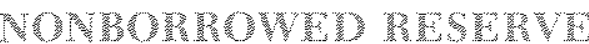

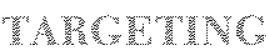

The controversy over base versus nonborrowed reserve targeting depends critically on the stability of the link between each of these reserve aggregates and nominal money. The stability of this link, in turn,

or total reserves, not nonborrowed reserves. It is sometimes argued that the Federal Reserve is essentially base or total reserve targeting because it first determines a total reserve path and, from that, its nonborrowed reserve path given an initial borrowing assumption. It would be total reserve targeting, however, only if it changed its nonbortowed reserves every time it recognized it was off its total reserve path. Recently, Gilbert and Trebing have shown that the Fed often knowingly stuck with its nonborrowed reserve path despite the fact that it correctly projected it would be off the total reserve path necessary to hit its short-run money target. $R$. Alton Gilbert and Michael E. Trebing, "The FOMC in 1980: A Year of Reserve Targeting," this Review (August/September 1981), pp. 2-16. 
depends on (a) the exogeneity of the respective reserve aggregate multiplier and (b) the exogeneity of the reserve aggregate. The first of these issues can be dealt with by considering the extent to which the money stock is exogenous under each target. ${ }^{9}$

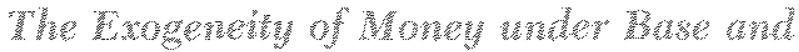

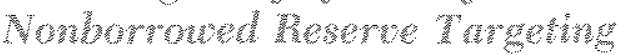

Consider the extent to which the money stock is exogenous under nonborrowed reserves and monetary base targeting - that is, determined only by the Federal Reserve's control over the target variable and the parameters of the model. This can be acomplished by observing the conditions required to make the money supply schedule vertical under the two regimes. Equation 1 indicates that the money stock is exogenously determined by the base if the public's demand for currency and time deposits and depository institutions' demand for excess reserves are unresponsive to interest rate changes $(\mu=\delta=\rho=0)$. If these conditions hold, equation 1 reduces to

(l) $\hat{\mathrm{M}}_{\mathrm{t}}=\frac{1+\mathrm{k}}{\mathrm{r}(1+\tau)+e+\mathrm{k}} \mathrm{B}_{\mathrm{t}}$.

The less interest-sensitive these factors are, the less interest-sensitive will be the money supply. If these factors are completely insensitive to the interest rate,

\footnotetext{
${ }^{9}$ In a recent Board study dealing with the observed historical stability of the monetary base multiplier, David lindsey and others discuss two types of muleiplier eadogeneity. First, they argue that the variability of the observed multipliers may be biased dowroward because they do not account for the possibility that the targeted level of the reserve aggregate maty have changed in response to an unanticipated change in some other factor. If, for example, the money supply took an unanticipated jump (becanse of an unanticipated jump in the demand for money) at the beginning of the intemeeting targeting period, the Federal Reserve might reduce its target for monborrowed reserves for the monetary base under base targeting. The result might be a larger observed mulaplier if the reduction in the reserve aggregate were larger than the reduction in the money supply from its manticipated level (of course it could be smaller it the money supply response was greater). This type of reserve aggregate endogeneity error applies to all potential reserve aggregates, but only if the Federal Reserve is actually targeting on it. Moreover, this type of reserve endogeneity is concerned only with the question of the observed stability of the multiplier; it has nothing to do with the issue of monetary control.

The second type of reserve endogeneity is the traditional type, in which factors that make up the various multiplers change with changes in other endogenous vartables (e.g., interest rates) in the system, as considered here. See, David Lindsey, et. al. "Monetary Control Experience Under the New Operating Procedures," New Monetary Control Procedures, Federal Reserve Staff Study, Volume II (Board of Governors of the Federal Reserve System, July 1981); Ballach, "How Controllable is Money Growth?" Johannes and Rasche, "Can the Reserves Approad to Monetary Control Really Work?" and "Predicting the Money Multiplier."
}

the money supply schedule becomes perfectly vertical, and the equilibrium money stock is exogenously controlled.

In contrast, the money stock is exogenous under nonborrowed reserve targeting only if the above conditions hold and if, simultaneously, $\alpha$, the interest responsiveness of borrowing from the Federal Reserve to the rate spread between the discount rate and the market interest rate, is zero. Under these conditions, equation 2 reduces to

(2) $\hat{\mathrm{M}}_{\mathrm{t}}=\frac{1+\mathrm{k}}{\mathrm{r}(1+\mathrm{t})+\mathrm{e}} \mathrm{NBR}_{\mathrm{t}}$

Thus, the conditions necessary for the Federal Reserve to control the money stock are more restrictive under nonborrowed reserve than under base targeting. Indeed, it is commonly accepted that excess reserves are interest-insensitive, and Johannes and Rasche recently have argued that the currency and time deposit ratios are fairly interest-insensitive as well. ${ }^{10}$ This is not the case, however, for depository institutions' borrowing. Casual observation shows a strong relationship between borrowing and the discotnt rate/market interest rate spread. Thus, the supply of money might exhibit greater interest sensitivity under nonborrowed reserve targeting than under base targeting. ${ }^{\text {. }}$

The importance of this for monetary control can be seen by noting that the less interest-sensitive the

\footnotetext{
${ }^{10}$ See Johannes and Rasche, "Predicting the Money Multiplier" for details.

"This question is more complicated in a nonlinear model. In the nonlinear case, the relative interest sensitivity of the money supply under base and NBR fargeting depends on the relative magnitude of these reserve agaregates and their multipliers. To illustrate this, let the money supply under base and NBR targeting be given by the expressions below.

$$
\begin{aligned}
& M^{s}=\mathrm{n}(i ; \mathrm{B}) \cdot \mathrm{B} \\
& \mathrm{M}^{\mathrm{s}}=\mathrm{m}(\mathrm{i} ; \mathrm{NBR}) \cdot \mathrm{NBR}
\end{aligned}
$$
}

Here, $m(\hat{i} ; B)$ and $m(1 ; N B R)$ denote multipliers that are functions of the interest rate, given either a base or NBP target. The difference in the interest responsiveness of the money supply ander base or NBR targeting is given by

$$
\frac{\partial m(i ; B)}{\partial i} \cdot B-\frac{\partial m(i ; N B R)}{\partial i} \cdot N B R
$$

This expression is less than or equal to zero if

$$
\frac{B}{N B R} \leq \frac{d m(i ; N B R\}}{a i}, \frac{\partial m(i ; B)}{\partial \mathrm{i}}
$$

Since the base is about four times as large as NBR, the base multiplier mist be about one-fourth as interest-responsive as the NBP multipier if the money supply under lase targeting is to be less interest-sensitive than under NBR targeting. Whether this condition holds depends on the relative magnitude of the structural parameters as discussed above. 
Figure 2

The Effect of Unanticipated Shifts in Money Demand and Supply

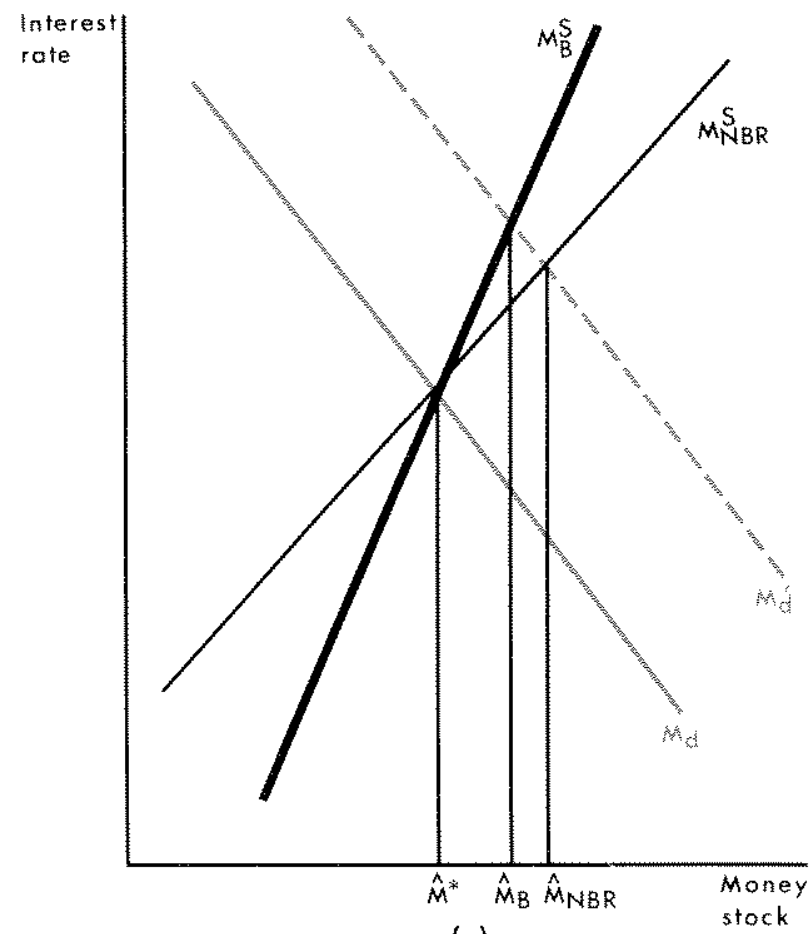

(a)

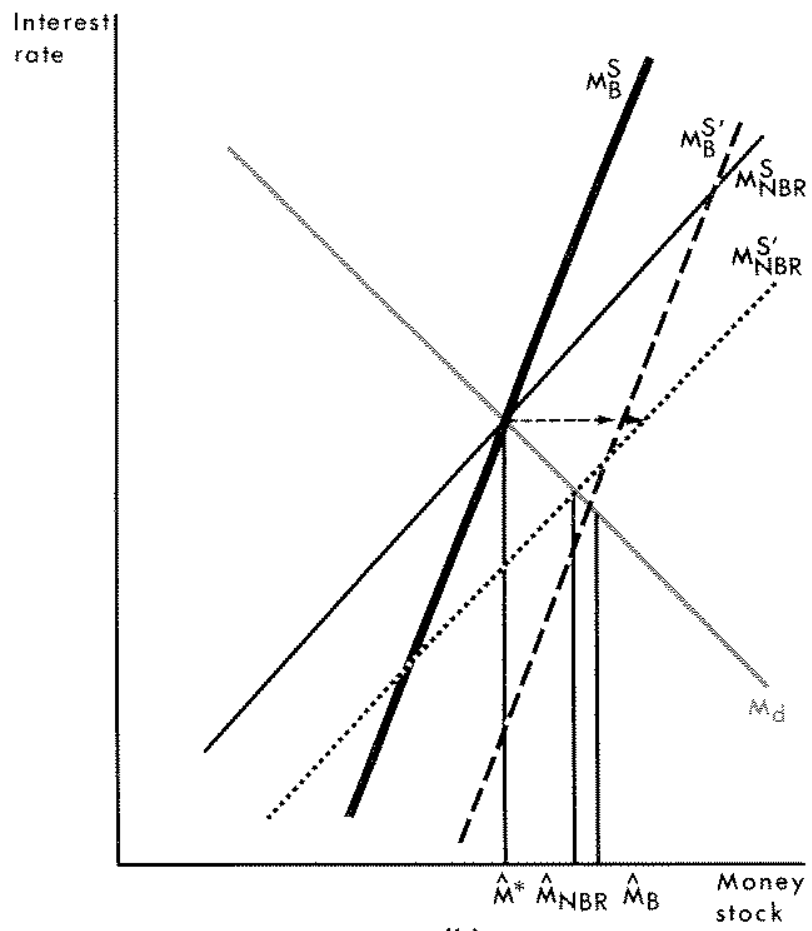

(b) money supply, the less responsive the equilibrium money stock will be to unanticipated shifts in money demand. This is illustrated in figure $2 a$, which shows the effect of an mnanticipated increase in the demand for money.

While it is more difficult to illustrate, the less interest-sensitive the supply of money, the more sensitive equilibrium money stock may be to manticipated changes in factors that affect the supply of money. (The exact relationship depends on the relative magnitude of certan parameters of the model.) This is illustrated in figure $2 b$. An unanticipated decrease, say, in excess reserves, shifts both $\mathrm{M}_{\mathrm{B}}^{\mathrm{s}}$ and $\mathrm{M}_{\mathrm{NBR}}$ to the right. Although the latter curve shift further, the resulting change in the money stock may be smaller. This is the result of the effect of a reduction in depository institutions' borrowing associated with the declining interest rate on the quantity of money supplied. The above result depends on the source of the supply-side shock. If the stpply-side shock comes from an unanticipated change in currency, the effect on the money stock will be larger than if it comes from excess reserves or time deposits.
The absolute magnitude of the differential effect of supply-side shocks under base and NBR targeting depends on the relative magnitude of the interest sensitivity of borrowing $(\alpha)$ and the demand for money $(\lambda)$. The less interest-sensitive is borrowing and the more interest sensitive the demand for money, the smaller will be this differential effect. If $\alpha$ is sufficiently small relative to $\lambda$, the money supply would be less responsive to supply-side shocks under base targeting, ${ }^{12}$

Given the above analysis, we would expect base targeting to result in more stable money grow th in most of the exogenous shoeks come from the demand side. If most shocks come from the supply side, however, base targeting may result in less stable growth. This last

\footnotetext{
Isthe requifed contition for smaller effects of supply-side shocks under base targetng is $(\lambda k+p)(1+k)<\alpha$. Since it is commonly assumed that $\rho$ is small this condition will hold only if $\lambda$ is large relative to $\alpha$. Most empirtal evidence on the demand for money suggests $A$ is very small. Sone recent estimates however, suggest a mach larger value of $\lambda$. See Daniel L. Thomton, "The Long-Rum and Short-Rin Demand for Money; Additional fevidence," Journal of Macroeconomics (Summer 1982), pp. 325-38.
} 
statement must be tempered by the fact that supplyside shocks resulting from exogenous changes in depository institutions' borrowing will not affect money under base targeting, but will affect it under NBR targeting. Thus, if borrowing is unstable, money may be less responsive to supply-side shocks from all somces under base targeting. ${ }^{13}$

\section{Endogeneity of the Monetary Base}

The above analysis explicitly assumes that both nonborrowed reserves and the monetary base can be controlled exogenously at any desired level. This is generally accepted to be true for nonborrowed reserves, though not for the monetary base. In fact, a principal objection to monetary base targeting is that the monetary base is endogenous.

In its most basic form, this objection argues that depository institutions' borrowing is functionally related to the level of open market operations. Thus, any attempt at hitting a monetary base target, by offsetting uncontrolled borrowing through open market operations, necessarily changes the level of borrowing that the system must offset. The problem of base endogeneity, while important, could be handled in part by tying the discount rate to the market interest rate.

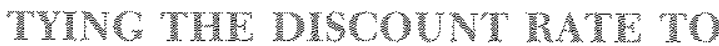 MAPI}

The interest responsiveness of borrowing could be substantially reduced by tying the discount rate to a market interest rate (i.e., $i_{t}=i_{t}+\Delta$, where $\Delta$ is a positive or negative constant). ${ }^{14}$ If this were done, borrowing would be unresponsive to interest rate

\footnotetext{
13. The error term in the borrowings equation is not present in the error term for the reduced-form money stock equation under base targeting. This, of course, assumes that information on depository instimation borrowing is avalable very quidly (it is currently avalable the next day). If the borrowing equation is unstable, as reported by a recent board study, then base targeting may stll be less sensitive to supply-side shocks. See "Impact of Discount Policy Procedures on the Effectiveness of heserve Targeting." New Monetary Control Procedures, Federal Reserve Staf Sudy. Volume 1 (Board of Guvernors of the Federal Reserve System, February 198i).

14 We do not say "eliminated" because it is unikely that tying the discount rate to any one market rate would eliminate all interestresponsive borrowing. This is die to the fact that different depository institutions may have porfolios of different asset that reflect their opportunity cost of borrowing. Hence, tying the discount rate to one asset may not suffice for every institution. Tying the discount rate to the federal funds rate, however, would probably reduce the interest responsiveness of borrowing for most depository institutions.
}

changes. This would substantially reduce the endogeneity of the base and, to this extent, make it much easier to hit and maintain a monetary base target.

Some have argued that the discount rate should be a penalty rate, that is, $\Delta>0$. This concern is probably overstated. The problem with depository institutions" borrowing is their interest sensitivity, not their level. Given the administration of the discount window, the level of aggregate borrowing will move inversely with $\Delta$. The value of the spread between the market rates and the discount rate will have little impact on its interest sensitivity. ${ }^{15}$

Tying the discount rate to market rates also has implications for nonborrowed reserve targeting. Under a tied discount rate, equation 2 could be rewritten as

$$
\begin{aligned}
\left(2^{\prime \prime}\right) \hat{M}_{t} & =\frac{\lambda}{\frac{(\lambda-\rho)(\mathrm{r}(1+\tau)+e)}{1+k}+(\mathrm{r} \mu+\delta)} \mathrm{NBR}_{t} \\
& +\frac{\beta(\mathrm{r} \mu+\delta)-\frac{\rho(\mathrm{r}(1+\tau)+e}{1+k}}{\frac{(\lambda-\rho)(\mathrm{r}(1+\tau)+e)}{1+k}+(\mathrm{r} \mu+\delta)} \hat{\mathrm{Y}}_{\mathrm{t}} .
\end{aligned}
$$

The multiplier in this equation is similar to the monetary base multiplier of equation 1. Thus, one might be tempted to conclude that controlling the money supply by targeting on the base or nonborrowed reserves essentially would be the same if the discount rate were tied to market interest rates. This is not the case. Changes in depository institutions' borrowing unrelated to interest rate changes will continue to affect the money supply under nonborrowed reserve targeting. This would not be true under base targeting since all changes in borrowing would be offset through open market operations. ${ }^{16}$

\footnotetext{
"The word "litle" is used here because Polakof has shown that borrowing increases at a decreasing rate as the rate spread widens. Making the discount rate a penalty rate might he a consideration if one believes Polkkols" "reluctance elasticty" is strong or if one believes that the administration of the discount window is highly variable. See M. $\mathrm{E}$, Polakoff, "Relnctance Elasticin, Least-Cost and Member-Bank Borrowing: A Suggested Integration,"Journal of Finance (March 1960), pp. 1-18. For a recent discussion of the role of the discount rate as a penaly rate, see Economic Report of the President (1982), pp. 67-68; and Bryon Higgins and Cordon H. Selion, fr., "Should the Discount Rate be a Penalty Rate?" Economic Review, Federal Reserve Bank of Kansas City (January 1981), тp. 3-10.

In this regard, if borrowing is unstable, tying the discount rate may not produce greater control under NBR targeting
} 


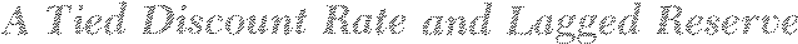 Anowativing}

While tying the discount rate to the market interest rate will reduce the endogeneity of the base under a system of CRA, this need not be the case under LRA. Under the present system of LRA, required reserves in the current week are determined by the level of deposits held two weeks previously. Thus, any discrepancy between the amount of reserves supplied by the Federal Reserve and the amount of reserves that depository institutions are required to hold must be made up either at the discount window or through changes in desired levels of excess reserves. Since historically excess reserves are relatively interestinsensitive, the discrepancy between the amount of reserves supplied and the amount of reserves required will likely be made up at the discount window. If the Federal Reserve attempted to hit a level of the monetary base that was inconsistent with the level of required reserves (given by deposit levels from the previous two weeks), the result would be an immediate change in the level of depository institutions borrow ing and a movement of the monetary base from its target level. Thus, it is argued, LRA precludes the Federal Reserve from hitting a shortmun monetary base target.

This argument is important; however, it has implications for short-run monetary control under both base and nonborrowed reserve targeting. If the target level for nonborrowed reserves is inconsistent with depository institutions required reserves, it produces a short-run change in borrowing, total reserves and, hence, money.

Furthermore, this argument fails to take account of the likely response by depository institutions to a monetary base operating procedure. A policy of offset ting all changes in borrowing to maintain a monetary base target may, at times, result in high levels of the federal funds rate; however, there is an upper limit to the federal funds rate that is established by depository institutions' credit demand. These institutions would be unwilling to pay an interest rate on short-term reserve adjustment funds in excess of the rate on marginal short-term loans for any extended period. Thus, depository institutions might increase their holdings of excess reserves if the Federal Reserve adopted a base targeting procedure. This response might permit the Federal Reserve to hit a base target, but would not guarantee better short-run monetary control. Any improvement in short-run monetary control in this instance depends critically on the volatility of excess reserves under a base targeting procedure. Thus, rather than being an objection to base targeting, this argument is simply an indictment of monetary control under LRA.

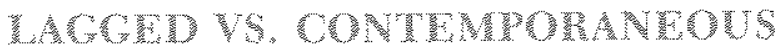

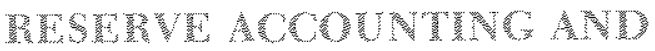

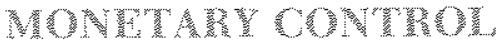

If the time subscript, $t$, is understood to be the end of a reserve maintenance week, the explicit effects of CRA and LRA for monetary control can be seen by comparing the model with the following required reserve equations:
(4) $\mathrm{RR}_{\mathrm{t}}=\mathrm{r}\left(\mathrm{D}_{\mathrm{t}}+\mathrm{TD}\right)$
CRA
(5) $R_{\mathrm{t}}=r\left(\mathrm{D}_{\mathrm{t} \cdots 2}+\mathrm{TD}_{\mathrm{t}-2}\right)$
LRA
(6) $\mathrm{RR}_{\mathrm{t}}=\mathrm{r}\left(\mathrm{D}_{\mathrm{t}}+\mathrm{T} \mathrm{D}_{\mathrm{t}-2}\right)$
Federal Reserve's proposal for CRA

These equations represent simplified versions of pure CRA, pure LRA (the present system) and the Federal Reserve's proposal for CRA, respectively. ${ }^{17}$ The analysis begins with a comparison of the model using equation 4 with the model using equation 5 , and ends with an analysis of the likely implications of the Federal Reserve's proposal.

To this point, the analysis has assumed equation 4 , so the effects of LRA can be seen by substituting equation 5 into the model. This modification affects the model in two ways: it weakens the contemporaneous link between the reserve aggregate and the equilibrium money stock, and it makes the model dynamic. ${ }^{18}$

These changes are illustrated by the following equations for the equilibrium money stock under base and NBR targeting when equation 5 replaces equation 4 :

$$
\text { (7) } \begin{aligned}
\hat{\mathrm{M}}_{\mathrm{t}} & =\frac{\lambda}{\frac{(\lambda-\rho)(\mathrm{k}+\mathrm{e})}{1+\mathrm{k}}+(\delta+\rho)} \mathrm{B}_{\mathrm{t}} \\
& -\frac{\mathrm{r}(1+\tau) \lambda}{\frac{(\lambda-\rho)(\mathrm{k}+\mathrm{e})}{(1+\mathrm{k})}+(\delta+\rho)} \mathrm{D}_{\mathrm{t}-2}
\end{aligned}
$$

${ }^{17}$ For a discussion of CRA and LRA as implemented, see $\mathrm{R}$. Alton Gilbert, "Lagged Reserve Requirements: Implications for Monetary Control and Bank Reserve Management," this Review (May 1980), pp. 7-20. The Board's proposal for CRA has a lag of two days. The reserve maintenance period ends on Monday, two days prior to the end of the reserve settlement week.

${ }^{1 / 3}$ Actually, the excess reserve equation may change with CRA or L.MA as well. Current levels of excess reserves would be related to deposits of the previous two weeks and the current market interest rate. This change is ignored for convenience. 


$$
\begin{aligned}
& -\frac{x \mu \lambda}{\frac{(\lambda-\rho)(k+e)}{(1+k)}+(\delta+\rho)} \hat{i}_{k-2} \\
& -\frac{\left[\left[(\delta+\rho)-\frac{\rho(k+e)}{1+k}\right]\right.}{\frac{(\lambda-\rho)(k+e)}{1+k}+(\delta+\rho)} \hat{Y}_{k}
\end{aligned}
$$

(8) $\hat{\mathrm{M}}_{\mathrm{t}}=\frac{\lambda}{\frac{(\lambda-\rho) \mathrm{e}}{1+\mathrm{k}}+(\delta+\alpha)} \mathrm{NBR}_{\mathrm{t}}$

$$
-\frac{\mathrm{r}(1+\tau) \lambda}{\frac{(\lambda-\rho) \mathrm{e}}{1+k}+(\delta+\alpha)} \mathrm{D}_{\ddagger-2}
$$$$
-\frac{\mathrm{r \mu \lambda}}{\frac{(\lambda-\rho) e}{1+\mathrm{k}}+(\delta+\alpha)}
$$

$$
\begin{aligned}
& +\frac{\alpha \lambda}{\frac{(\lambda-\rho) e}{1+k}+(\delta+\alpha)} i d_{t} \\
& +\frac{\beta\left[(\delta+\alpha)-\frac{\rho e}{1+k}\right]_{\hat{Y}_{\xi}}}{\frac{(\lambda-\rho) e}{1+k}+(\delta+\alpha)}
\end{aligned}
$$

The first of these changes can be seen by noting that neither the reserve ratio $(r)$ nor the time deposit ratio (r) appears in the contemporaneous multipliers for the base and NBR. Indeed, NBR are contemporaneously linked to money, through non-interest-rate effects, only via excess reserves and borrowings. The reserve aggregates provide a link to current money creation primarily through their link to current deposits. LRA severs part of this link. (1t should be noted, however, that LRA does not eliminate completely the contemporaneous link between the money stock and eithe: reserve aggregate.) ${ }^{19}$

\footnotetext{
${ }^{19} \mathrm{Yt}$ is sometimes argued that there is no contemporaneous link between deposit creation and reserves independent of its effect on market interes tates, because depository institutions are free to create all the deposits they whs in this period without any consid. eration about the current level of reserves (e., g. LeRoy, "Mone. tary Control Under Lagged Reserve Acounting"). This argument clearly ignores the role of currency and excess reserves in estab. lisking a contemporaneous link between the reserve aggregate and the money stock. It is easy to show that current deposits are related to current base mider LRA, even if the interestresponsiveness of currency and excess reserves are zero. From the appendix: if $p=\delta=0$, then $\mathbf{M}_{\mathbf{t}}=(1+k) /(k+e) B_{t}$. Pesek and Saving have made this point in a simple money muliplier model when there were no reserve requirements. See Boris P. Pesek and Thomas R. Saving, The Foundations of Money and Banking (Macmillan Co., 1968), pp. $76-78$.
}

The explicit dynamics of the money stock under LRA are seen by noting that lagged deposits and in terest rates are included in the equilibrium money stock equations. NBR and the monetary base not only inflience the level of money immediately, but have lagged effects via their influence on deposits and interest rates. These variables, in tum, affect future money. It can be shown that if the dynamic system is stable, the long-run base multiplier is identical to the static base multiplier of equation 1 . Thus, if the Federal Reserve were to achieve and maintain some target level of the base, the expected value of the long-1un equilibrim money stock would, ceteris paribus, be the same as that obtained under CRA. ${ }^{20}$

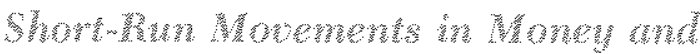

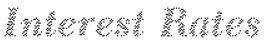

Despite the fact that the return to CRA has no consequences for long-run monetary control, it does have some implications for short-run movements in money and interest rates. The following analysis can be carried ont in terms of either base or NBR targeting; however, the results are presented only for base targeting.

The analysis begins with a simple graphic presenta" tion of the model under base targeting in figure $3 . \mathrm{M}_{\mathrm{s}}^{\mathrm{s}}$ and $\mathrm{M}_{i}^{s}$ denote the money supply schedules under CRA and $\mathrm{RA}$, respectively. Under fairly reasonable conditions, the money supply schedule is flatter under LRA. ${ }^{21}$ Again, the money demand equation is drawn for a fixed income level. The curves are drawn to intersect for ease of illustration.

\footnotetext{
20 This point has been made by Lawenberg, athoagh in at slightly different context. See Daniel E. Latufenberg "Contemporaneous Versus Lagged Reserve Acounting," Joumal of Money, Credit and Banking (May 1976), pp. 239-45. This result is more logica than it first appears. For example, one would not expect the introduction of LRA to have any impact on money creation if depository instifutions had not previonsly adjusted their required reserves daring the current week tuder ChA. Thas, we night expert ERA to affect interest rates and money only to the extent that if forces the system to follow a different aggregate reserve adjustment path than it would have followed ander CRA.

FThe condition is that

$$
\mu>\frac{(1+\tau)(\delta+p)}{(e+k)}<0
$$

Since $(1+\pi) /(e+k)$ is greater than one, this condition is likely to hold. If the interest sensitivity of time deposits, $\mu$, is sufficiently negative, however, the LRA conld be steeper than the CRA cenve. If this were the case, the results of this section wouk be reversed. Because of the simplicity of his model, Lanferberg obtains the above result by ignoring this condition. See Lautenberg, "Contemporaneous Versus Lagged Reserve Accounting."
} 


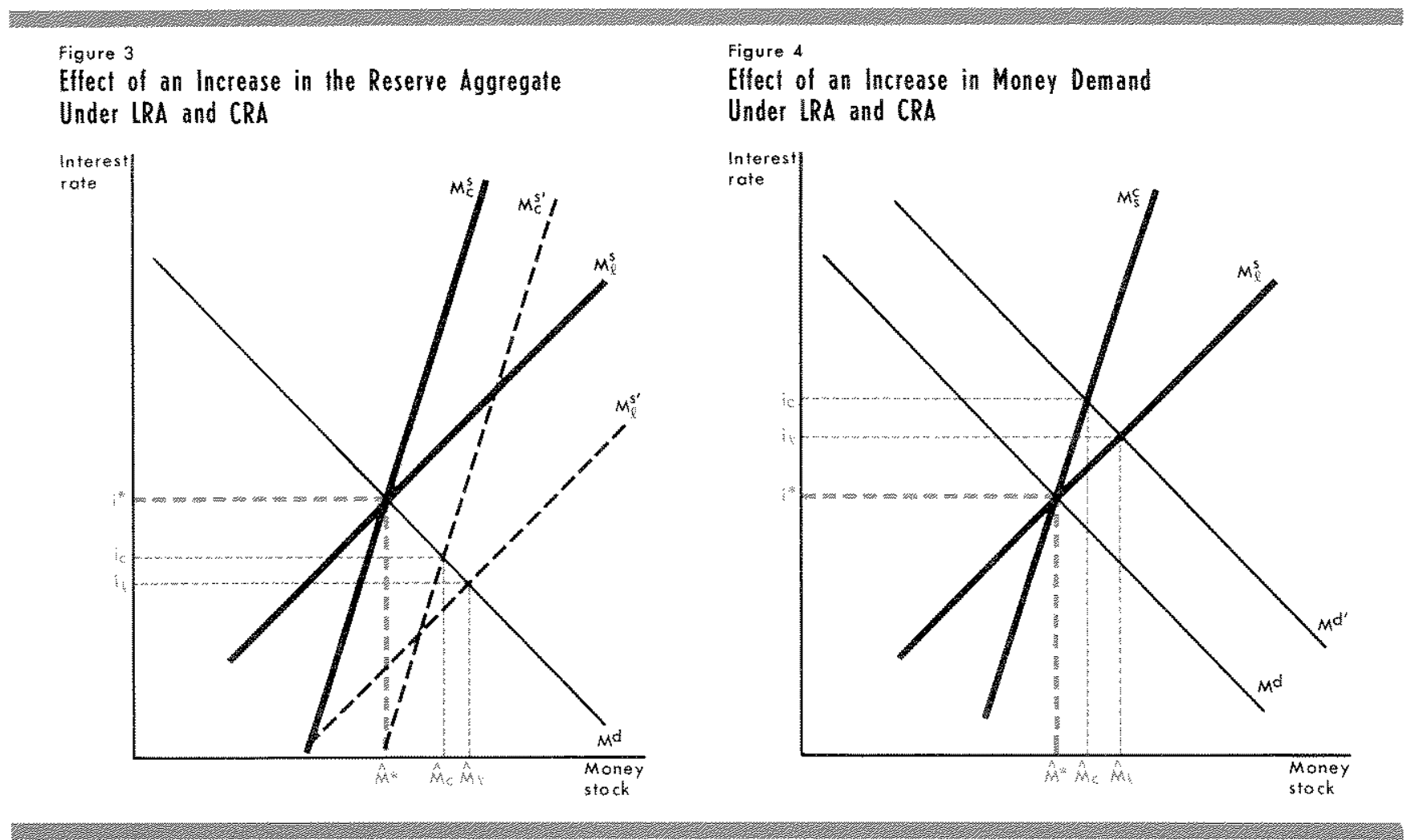

The effect of changes in Federal Reserve actions on the money stock can be illustrated via figure 3 . For example, suppose that the monetary disturbance comes through an increase in the base. The increase in the base shifts both $\mathrm{M}_{\mathrm{c}}^{\mathrm{s}}$ and $\mathrm{M}_{\mathrm{s}}^{\mathrm{s}}$ to the right. Because the multiplier is larger under LRA than under CRA, the Me curve shifts further and the new equilibrium level of money is larger. ${ }^{22}$ As a result, both the initial increase in the money stock and the initial decrease in the interest rate are larger under LRA.

A different result is obtained if the monetary disturbance occurs through a change in the demand for money, as illustrated in figure 4 . The increase in the demand for money results in a larger initial increase in the money stock and a smaller initial increase in the interest rate under LRA. If all money shocks are associated with changes in money demand due to unanticipated changes in the level of income, the move back to CRA would result in less short-run money stock and more interest-rate variability. If all money shocks are associated with changes in the policy control variable,

22 The condition required for the equilibrim money stock to be larger is that

$$
\mu<\frac{-(\lambda-p)(1+t)}{1+k}>0 .
$$

The same condition is required for both base and NBR targeting. the return to CRA would reduce the short-run variability of both money and interest rates.

In either case, however, the short-run money stock initially overshoots its long-run equilibrium. In the former case, the overshoot is due to the fact that interest rates fall too far in response to an increase in the policy aggregate, while in the latter, it is due to the fact that they do not rise enough in response to an increase in money demand. This initial overshooting of money may have repercussions in subsequent periods as depository institutions attempt to obtain reserves to support the current overexpansion of deposits. The effect of this dynamic response on the variability of money and interest rates is an empirical question. ${ }^{23}$

\footnotetext{
ssee Laufenberg, "Contemporaneous Versus Lagged Reserve Accounting." As noted, the introduction of LRA makes the model dynamic and thus, the model with LRA follows an adjustment path towath the longrun equilibrium. This path differs with the dynamic structure of the model. A comparison of one dymamic adiustment path with another is relevant only if the dynamic structures are well-specified. In this regard, the conclusions concerning the variability of money and interest rates reached by Laufenberg, based on a comparison of the dynamic atjustanent of the CRA and LRA models are misleading. See Daniel $L_{\text {. Thor }}$ tom, "Lagged and Contemporaneous Reserve Acownting and the Variance of Money and Interest Rates," nupublished paper, Federal Reserve Bank of St. Louis (1982). The oscillatory nature of the adiustrnent of money and interest rates to their longran equilibriam under LRA noted by Laufenberg is disenssed in the appendix.
} 


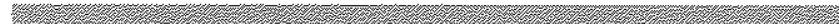

Figure 5

\section{The Money Supply Under the Board's}

Proposal for CRA

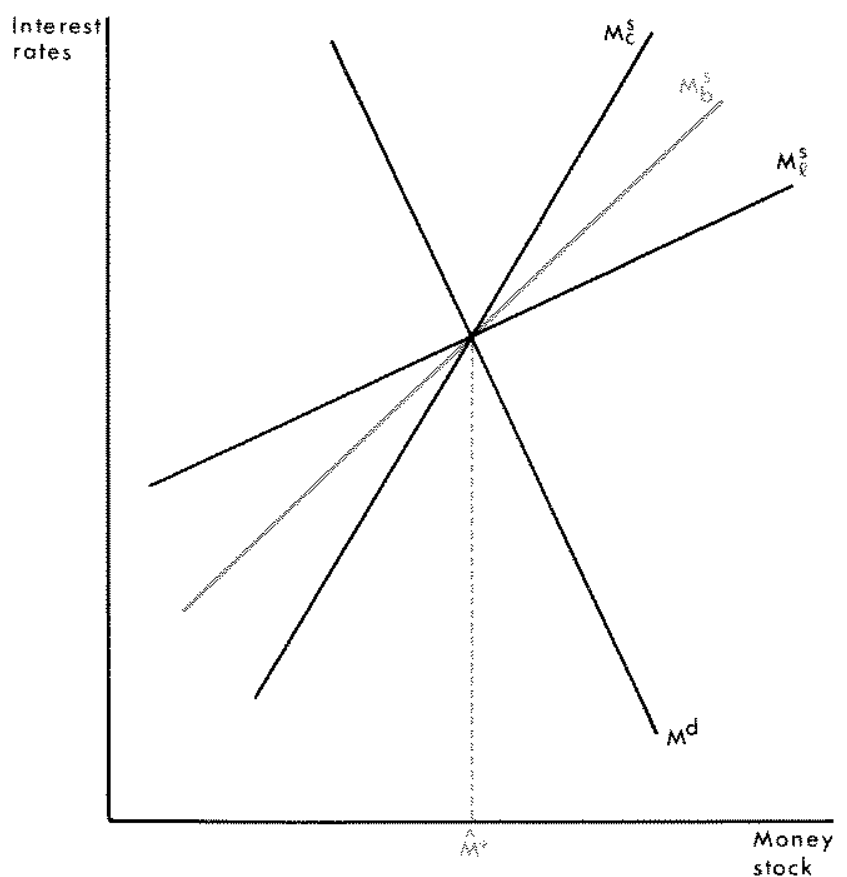

The effect of the Federal Reserve's proposal for CRA can be seen by noting that the money supply schedule under the Board's proposal, denoted $\mathrm{M}_{\mathrm{b}}^{\mathrm{s}}$, lies between the CRA and LRA curves, as illustrated in figure 5. Furthermore, the curve will shift further than the CRA curve, but not as far as the LRA for a given change in the monetary base. If most money shocks are associated with changes in the policy control variable, the Federal Reserve's proposal should improve the shortrun stability of both money and interest rates. If most shocks are associated with unanticipated changes in the demand for money, the result will be more stable money and less stable interest rates.

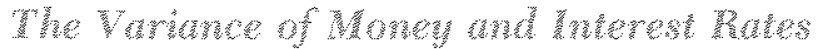

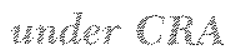

Given the above analysis, one might be tempted to conclude that random variations in the factors that affect the money supply will cause both money and interest rates to be more variable under LRA, while random variations in the demand for money will cause money to be more variable and interest rates to be less variable. Thus, one might suspect that the movement from CRA to LRA would increase the variance of money and may increase the variance of interest rates, depending on the relative magnitudes of the variances associated with the factors that affect supply and demand. While the basic intuition that leads to this conclusion is correct, it fails to account for possible Federal Reserve reaction to random changes in time deposits.

Under both CRA and LRA, random changes in time deposits, TD, affect the demand for required reserves and, hence, the equilibrium money stock and the interest rate. Under LRA, however, the effect of a random change in time deposits does not manifest itself for two periods. If such changes were identiffed with 100 percent accuracy and if the Federal Reserve made temporary, compensatory changes in the exogenous reserve aggregate, random fuctuations in time deposits two weeks previous would have no effect on either the current money stock or the current interest rate. If the variance of the time deposits is sufficiently large, the variance of money and interest rates may be less under LRA than under CRA. The critical issue is the extent to which the Federal Reserve correctly identifies and offsets random shifts in time deposits. ${ }^{24}$

This result is illustrated as follows: Let $V\left(M_{t}^{c}\right)$ and $\mathrm{V}(\mathrm{M})$ denote the variance of the money stock under CRA and LRA, respectively. If the Federal Reserve correctly identifies random changes in time deposits, it is easy to show that

and

$$
\begin{aligned}
& V\left(M_{t}^{c}\right)=\sigma_{1}^{2}+\sigma_{M T}^{2} \\
& V\left(M_{t}^{2}\right)=\sigma_{2}^{2},
\end{aligned}
$$

where $\sigma_{M T}^{2}$ is the variance in money associated with the demand for time deposits, $\sigma_{1}^{2}$ is the variance associated with the other random components of the money stock under CRA, and $\sigma_{2}^{2}$ is the variance of money under LRA. It can be shown that $\sigma_{2}^{2}>\sigma_{1}^{2}$. Thus, the variance of the money stock would be larger under LRA, all other things constant. The loss of the variance of time deposits $\left[\sigma_{\mathrm{MT}}^{2}\right.$ does not appear in the expression for $\left.V\left(\mathbf{M}_{t}\right)\right]$, however, makes the variance of money under LRA smaller. The reduction in variance associated with the removal of this source of variation could more than offset the increase in variance due to other

\footnotetext{
${ }^{24}$ Furthermore, if individual depository institutions anticipated the effects of their collective actions on interest rates, the systematic deposit overexpansions that we have noted need not occur; consequently, the greater money and interest rate yolatility associated with differences in the slopes of the short-run money schedule znder LRA need not materialize. This point has been made by Edgar L. Feige and Robert T. McGee, "Federal Reserve Polic and Interest Rate Instability," The Financial Review (May 1982), pp. $50-62$.
} 
factors. ${ }^{25}$ Thus, contrary to the common belief, no general conclusion can be reached about the relative variance of money under LRA and CRA. It is an empirical issue. ${ }^{26}$

This analysis can be extended to the Federal Reserve's proposal for CRA. If the variance of the money stock under the Board's proposal is denoted as $V\left(M_{t}^{b}\right)$, it is easy to show that $V\left(M_{t}^{b}\right)<V\left(M_{t}\right){ }^{27}$

The question of the relative variance of interest rates under LRA or CRA has an ambiguous answer. If the reduction in variance associated with correctly identifying random changes in time deposits is ignored, the variance of interest rates will be smaller under CRA if the variance associated with money demand is small relative to the variance associated with the factors that

\footnotetext{
${ }^{25}$ This result is even stronger when it is recognized that variances of borrowings and excess reserves may be affected by the reserve accounting structure. There is evidence that both of these error structures changed with the move to LRA in 1968. See Abert $E$. Burger, "Lagged Reserve Requifements: Their Effects on Federal Reserve Operations, Money Market Stabilizy. Member Banks and the Money Supply Process," unpublished paper for the Federal Reserve Bank of St. Louis (1971); and Board of Gov. ernors, "Impact of Discount Policy Procedures on the Effectiveness of Reserve Targeting,"

${ }^{26}$ See Poole, "Federal heserve Operating Procedures: A Survey and Evaluation of the Historical Record Since October 1979;" LeRoy, "Monetary Control Under Lagged Reserve Accounting;" and David S. Jones, "An Empirical Analysis of Monetary Control Under Contemporaneous and Lagged Reserve Accounting," Federal Reserve Bank of Kansas City Working Paper 82-002 (March 1982).
}

Furthermore, the enpirical work to date does not provide an unambiguous answer to this question. Early empirical work by Burger, Coats, Poole and Lieberman suggested that the movement to LRA in 1968 resulted in greater instability of the federal funds rate. Recent work by Feige and McGee, however, suggests that the movement to LRA actually reduced the funds rate variability. Poole and Lieberman report somewhat less stable money growth under LRA; however, in another study, Feige and McGee report slight increases in money and reserve predictability under LRA during the reserve-targeting period, and a substantial increase in the predictability of the federal funds rate. See Burger, "Lagged Reserve Requirements; Their EFects on Federal Reserve Operations, Money Market Stability, Member Banks and the Money Supply Process;" Warren L. Coats, "Lagged Re. serve Accounting and the Money Supply Mechanism," Journal of Money, Credit and Banking (May 1976), pp. 167-80; Feige and McGee, "Federal Reserve Policy and Interest Rate Instability," pp. 50-61; Edgar L. Feige and Robert T. McGee, "Has the Federal Reserve Shifted From a Policy of Interest Rate Targets to a Policy of Monetary Aggregate Targets? An Application of Exogeneity Test Procedures," Journal of Money, Credit and Banking (November 1979), pp. 381-404; Edgar L. Feige and Robert T. McGee, "Money Supply Control and Lagged Reserve Accounting," Journal of Money, Credit and Banking (November 1977), pp. $536-51$.

${ }^{2 \pi}$ The reader is cautioned that this analysis of the variance of money and interest rates ignores variability through time associated with the dynamic structure of the model. affect the money supply, ${ }^{28}$ The same conclusion holds for a comparison of the Federal Reserve's proposal for CRA with LRA.

We have shown that if we account for a possible reduction in the variance of interest rates under LRA associated with correctly identifying random changes in time deposits, the variance of interest rates under LRA could be smaller than under CRA even if money demand were less variable than the money supply. This conclusion would not hold for the Federal Reserve's proposal, however, since time deposits enter LRA and it in the same way.

Thus, while an analysis of this model suggests that the Federal Reserve's proposal for CRA may reduce the variance of money compared with the present system of LRA, its impact on the variance of interest rates is ambiguous. ${ }^{29}$

\section{GONCTUMONS}

This article reviews three frequently suggested changes in Federal Reserve operating procedures to achieve more stable short-run monetary control: monetary base targeting, tying the discount rate to the market interest rate and adopting a system of contemporaneous reserve accounting.

Since the conditions necessary for money to be exogenous are less restrictive for base than for nonborrowed reserve targeting, adopting a base targeting procedure would likely result in greater short-run monetary control if most of the shocks to the money supply come from the demand side. If most of the shocks come from the supply side, then base targeting

\footnotetext{
${ }^{28}$ In this regard, there has been a great deal of concern about the stability of money demand in recent years. See, for example, Michael J. Hamburger, "Behavior of the Money Stock: Is There a Puzzle?" Journal of Monetary Economics (July 1977), pp. 265 88 ; G. S. Laumas and David E. Spencer, "The Stability of the Demand for Money: Evidence from the Post-1973 Period " Review of Economics and Statistics (August 1980), pp. 455-59; and R. W. Hafer and Scott $E$. Hein, "Evidence on the Temporal Stability of the Demand for Money Relationship in the United States," this Review (December 1979), pp. 3-14; and "The Shift in Money Demand: What Really Happened?" this Review (February 1982), pp. $11-16$.

${ }^{20}$ The Board has also considered a provision for staggered-reserve accounting. The effect of this controversial provision on short-run variability of money and interest rates remains a question. For a discussion of the effects of staggered-reserve accounting, see Michael L. Bagshaw and William T. Gavin, "Stability in a Model of Staggered-Reserve Acconnting," Federal Reserve Bank of Cleveland. Working Paper 8202 (August 1982); and William "T. Gavin, "The Case for Staggered-Reserve Accounting," Federal Reserve Bank of Cleveland Economic Review, (Spring 1982), pp. $30-36$.
} 
may result in less stable monetary growth. This conclusion depends critically on the relative interest sensitivity of the demand for money and depository institution borrowing. The more interest sensitive is the former and less interest sensitive is the latter, the more stable money growth will be under base targeting relative to NBR targeting. Furthermore, if depository institution borrowing is highly variable, base targeting may be more stable, even if the shocks come from the supply side, since money will be unresponsive to fluctuations in borrowing under base targeting.

Monetary control under base targeting could be enhanced further by tying the discount rate to a market interest rate. This would reduce substantially the interest sensitivity of borrowing and make it easier to hit a monetary base target. Adopting a system of contem- poraneous reserve accounting also should make it easier to hit a base target, since it would no longer be necessary for borrowing to respond to differences between a predetermined level of required reserves and an amount of reserves consistent with the base target, as under the present system of LRA.

It is not certain whether the return to a system of contemporaneous reserve accounting on all deposits would increase or reduce the variance of money and interest rates. The Federal Reserve's proposal for contemporaneous reserve accounting, however, will likely reduce the variability of money. Furthermore, it will likely reduce the variability of interest rates, if the variance of the money demand schedule is sufficiently small relative to the variance of the money supply schedule.

\section{APPENDIX}

The purpose of this appendix is fourfold. First, it presents the system of reduced-form equations for base and NBR targeting under CRA. Second, it presents the reduced-form equations under LRA. Third, the long-rum base multiplier under LRA is derived and discussed. Finally, analytical results for the variance of the endogenous variables for base and NBR targeting and for CRA and LRA are presented and discussed. In what follows, we will denote the expected value of the variable with a hat, e.g., $\mathrm{E}\left(\mathrm{M}_{\mathbf{t}}\right)=\hat{\mathbf{M}}{ }^{{ }^{\prime}}$

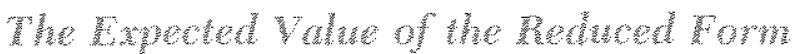

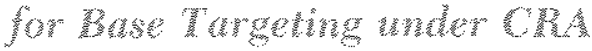

$$
\begin{aligned}
& \hat{M}_{\mathrm{t}}=\frac{\lambda}{\Delta 0} B_{\mathrm{t}}+\frac{\beta\left[(\mathrm{r} \mu+\delta+\rho)-\frac{\rho(\mathrm{r}(1+\tau)+\mathrm{e}+\mathrm{k})}{1+\mathrm{k}}\right]}{\Delta_{0}} \hat{\mathrm{Y}}_{\mathrm{t}} \\
& \hat{\mathrm{i}}_{\mathrm{q}}=\frac{1}{\Delta_{0}} B_{\mathrm{t}}-\frac{\beta(\mathrm{r}(\mathrm{l}+\tau)+\mathrm{e}+\mathrm{k}) /(1+\mathrm{k})}{\Delta_{0}} \hat{\mathrm{Y}}_{\mathrm{t}}
\end{aligned}
$$

'The symbol $\hat{Y}$, is used here in explicit recognition that the Federal Reserve must forecast aggregate income in order to control the nominal money stock.

$$
\begin{aligned}
& \mathrm{NBR}_{\mathrm{t}}=\frac{\frac{(\mathrm{\lambda}-\mathrm{p})(\mathrm{r}(1+\pi)+\mathrm{e})}{(1+\mathrm{k})}+(\mathrm{r} \mu+\delta+\alpha)}{\Delta_{0}} \mathrm{~B}_{\mathrm{i}} \\
& -\frac{\beta((r(1+\tau)+e)(\alpha-p)+k(r \mu+\delta+\alpha)]}{1+k} \hat{Y}_{t} \\
& -\alpha i d t \\
& \hat{D}_{\mathrm{t}}=\frac{(\lambda-p) /(1+k)}{\Delta_{0}} B_{\mathrm{t}}+\frac{\beta(1 \beta+\delta+p) /(1+k)}{\Delta_{0}} \hat{\mathbf{Y}}_{\mathrm{t}} \\
& \text { where } \Delta_{0}=\frac{(\lambda-p)(r(1+\tau)+e+k)}{1+k}+(k+\delta+\rho)
\end{aligned}
$$

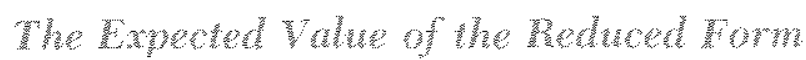

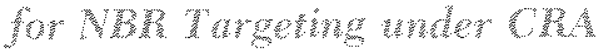

$$
\begin{aligned}
& \hat{M}_{\mathrm{t}}=\frac{\lambda}{\Delta_{1}} \mathrm{NBB}_{\mathrm{t}}+\frac{\beta\left[(\mathrm{r} \mu+\delta+\alpha)-\frac{\rho(\mathrm{r}(1+\mathrm{t})+\mathrm{e})}{1+\mathrm{k}}\right]_{\hat{Y}_{\mathrm{t}}}}{\Delta_{1}}
\end{aligned}
$$




$$
\begin{aligned}
& +\frac{\alpha \lambda}{\Delta_{1}} \mathrm{id}_{\mathrm{i}} \\
& \hat{f}_{\mathrm{t}}=\frac{1}{\Delta_{1}} \mathrm{NBR}_{\mathrm{t}}-\frac{\beta(\mathrm{r}(1+\tau)+\mathrm{t}) /(1+k)}{\Delta_{1}} \hat{\mathrm{Y}}_{\mathrm{t}}+\frac{\alpha}{\Delta_{\mathrm{l}}} \mathrm{id}_{\mathrm{t}} \\
& \hat{\mathbf{B}}_{\mathrm{t}}=\frac{\frac{(\mathrm{A}-\beta)(\mathrm{r}(1+\tau)+e+\mathrm{k})}{(1+\mathbf{k})}+(r \mu+\delta+\rho)}{\Delta_{1}} \mathrm{NBR}_{\mathrm{q}} \\
& -\frac{\beta[(\mathbf{r}(1+\tau)+e)(\alpha-\beta)+(\mathrm{r} \mu+\delta+\alpha) k]}{(I+k) \Delta_{1}} \hat{\mathbf{Y}}_{1} \\
& +\frac{\alpha\left[\frac{(\lambda-p)(r(1+\tau)+e+k)}{1+k}+(r \mu+\delta+\rho)\right]}{\Delta_{1}} i d_{t} \\
& \hat{\mathrm{D}}_{\mathrm{t}}=\frac{(\lambda-\rho \mathrm{h} /(1+\mathrm{k})}{\Delta_{\mathrm{l}}} \mathrm{NBR}_{\mathrm{f}}+\frac{\beta(\mathrm{r} \mu+\delta+\alpha) /(1+\mathrm{k})}{\Delta_{1}} \hat{\mathrm{Y}}_{\mathrm{t}} \\
& +\frac{\alpha(\lambda-\rho) /(1+k)}{\Delta_{1}} \mathrm{id}_{\mathrm{t}}
\end{aligned}
$$

where $\Delta_{1}=(\lambda-\rho)\left[\frac{\mathrm{r}(1+\tau)+\mathrm{e}}{1+\mathrm{k}}\right]+(\mathrm{r} \mu+\delta+\alpha)$.

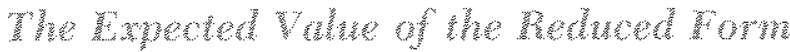

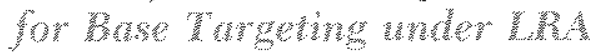

$$
\begin{aligned}
& \hat{\mathbf{M}}_{\mathrm{t}}=\frac{\lambda}{\Delta_{2}} \mathrm{~B}_{\mathrm{t}}-\frac{\mathrm{r}(\mathbf{I}+\boldsymbol{T}) \lambda}{\Delta_{2}} \mathrm{D}_{\mathrm{t}-\mathrm{2}} \\
& -\frac{r \mu \lambda}{\Delta_{2}} i_{4-2}-\frac{\beta\left[(\rho+\delta)-\frac{(\rho(k+e)}{1+k}\right]}{\Delta_{2}} \hat{\mathbf{Y}}_{t} \\
& \hat{\mathrm{D}}_{\mathrm{t}}=\frac{(\lambda-\rho) /(1+\mathrm{k})}{\Delta_{2}} B_{\mathrm{t}}-\frac{\mathrm{r}(\mathrm{I}+\mathrm{r})(\lambda-\rho) /(1+\mathrm{k})}{\Delta_{2}} D_{\mathrm{t}-2} \\
& -\frac{r \mu(\Lambda-\rho) /(1+k)}{\Delta_{2}} i_{1-2} \\
& +\frac{\beta(\rho+\delta) /(1+k)}{\Delta_{2}} \hat{Y}_{t} \\
& \hat{i}_{\mathrm{t}}=-\frac{1}{\Delta_{2}} B_{1}-\frac{r(1+\tau)}{\Delta_{2}} D_{1-2}-\frac{r \mu}{\Delta_{2}} i_{t} \ldots z \\
& -\frac{\beta(k+e) /(1+k)}{\Delta_{2}} \hat{Y}_{t} \\
& \mathrm{NBR}_{\mathrm{r}}=\frac{\frac{(\lambda-p) e}{1+k}+(\delta+\alpha)}{\Delta_{2}} \mathbf{B}_{\mathrm{r}} \\
& +\frac{r(1+\tau)\left[\frac{(\lambda-\alpha) k+(\rho-\alpha)}{1+k}\right]}{\Delta_{2}} D_{t-2}
\end{aligned}
$$

$$
\begin{aligned}
& +\frac{r \mu\left[\frac{(\lambda-\alpha) k+(\rho-\alpha)}{1+k}\right]}{\Delta_{2}} j_{i_{t-2}} \\
& -\frac{\beta(\delta+\alpha)(k+e)-e(\delta+\rho))(1+\mathrm{d})}{\Delta_{2}} \hat{\mathbf{Y}}_{\mathrm{t}} \\
& -{\alpha i d_{t}}
\end{aligned}
$$

where $\Delta_{2}=\frac{(\lambda-p)(k+e)}{1+k}+(\delta+p)$

Several interesting observations should be made about the above. First, the discount rate enters the reduced-form under base targeting only in the NBR equation. This merely reflects the fact that if the Federal Reserve is to hit a base target, it must change NBR proportionally to the change in the discount rate. Thus, changes in the discount rate cannot alter policy with respect to either the money supply or interest rates independent of the base target. This would not be true of NBR targeting. Under NBR targeting, changes in the discount rate produce effects on money and interest ates independent of the target level of NBR.

Second, it is easy to show the conditions under which the initial change in the equilibrium money stock is larger under LRA than under CRA. Note that

$\left.\frac{\Delta \hat{\mathrm{M}}_{\mathrm{t}}}{\Delta \mathrm{B}_{\mathrm{q}}}\right|_{\mathrm{LRA}}-\left.\frac{\Delta \hat{\mathrm{M}}_{\mathrm{t}}}{\Delta \mathrm{B}_{\mathrm{t}}}\right|_{\mathrm{CRA}}>0$

implies

$\frac{\lambda}{\frac{(\lambda-\rho)(\mathrm{e}+\mathrm{k})}{1+\mathrm{k}}+\delta+\rho}-\frac{\lambda}{\frac{(\lambda-\rho)(\mathrm{r}(1+\gamma)+\mathrm{e}+\mathrm{k})}{1+\mathrm{k}}+(\mathrm{r} \mu+\delta+\rho)}>0$.

This condition will hold if

$\mu<-\frac{(\lambda-\beta)(1+\tau)}{1+k}$.

The term on the right hand side of this inequality will be positive on the reasonable assumption that $|\lambda|>|\rho|$. The condition for the change in the money stock under the Federal Reserve's proposal to be less than under LRA is

$\mu<-\frac{(\lambda-\rho) \tau}{1+k}$

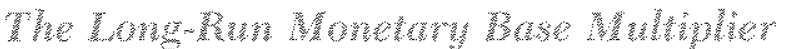

The above system based on LRA is dynamic in that lagged endogenous variables, $D_{-2}$ and $i_{t-2}$, appear on 
the right-hand side of the reduced-form. ${ }^{2}$ If we assume, for simplicity, that $\hat{Y}_{t}=0$ for all then it is easy to show that $\hat{\mathrm{M}}_{\mathrm{t}}$ can be expressed as the following distributed lag by successive substitution.

$\hat{M}_{\mathrm{t}}=\frac{\lambda}{\Delta_{2}} B_{\mathrm{t}}+\frac{\lambda \varphi}{\Delta_{2}} B_{\mathrm{t}-2}+\frac{\lambda \varphi^{2}}{\Delta_{2}} B_{\mathrm{q}-\mathrm{3}}+\ldots$

where $\varphi=-\left[\frac{r(1+\tau)(\lambda-\rho)+r \mu(1+k)}{(1+k) \Delta_{2}}\right]$.

Now if we let the base be constant for all t (i.e., $B_{t}=$ $B_{t-2}=B_{t-4}=\ldots=\bar{B}$ ), we get

$\hat{\mathrm{M}}_{1}=\frac{\overline{\mathrm{B}} \lambda}{\Delta_{2}}\left[1+\varphi+\varphi^{2}+\varphi^{3}+\ldots\right]$

Using the formula for summing a geometric series, and taking the limit, we have

$\hat{M}_{t}=\lim _{n \rightarrow \infty} \frac{\bar{B} \lambda}{\Delta_{2}}\left[\frac{1-\varphi^{n}}{1-\varphi}\right]$.

The sum on the right-hand side of the above equation is finite if $\varphi^{n} \rightarrow 0$ as $n \rightarrow \infty$. Under this condition,

$\hat{\mathrm{M}}_{\mathrm{q}}=\frac{\overrightarrow{\mathrm{B}} \lambda}{\Delta_{2}}\left[\frac{1}{1-\varphi}\right]$.

Substituting in for $\varphi$, we get

$$
\begin{aligned}
\hat{\mathrm{M}}_{\mathrm{\varepsilon}} & =\frac{\overline{\mathrm{B}} \lambda}{\Delta_{2}} \frac{1}{\left[1+\frac{\mathrm{r}(1+\tau)(\lambda-p)+r \mu(1+\mathrm{h})}{(1+\mathrm{k}) \Delta_{2}}\right]} \\
& =\overline{\mathrm{B}} \lambda\left[\frac{1}{\Delta_{2}(1+\mathrm{k})+\mathrm{r}(1+\tau)(\lambda-p)+(r \mu)(1+\mathrm{k})}\right] .
\end{aligned}
$$

Substituting in for $\Delta_{2}$, we get

$$
\hat{M}_{1}=\bar{B} \frac{\lambda}{\frac{(\lambda-\rho)[r(1+\tau)+k+e]}{1+k}+(\delta+\rho+r \mu)} .
$$

Comparing this multiplier with the base multiplier under CRA, we see that they are identical. Thus, LRA makes the system explicitly dynamic but does not affect the long-run equilibrium.

The above solution, however, does require the stability condition $|\varphi|<1$. The system may converge

${ }^{2}$ The inclusion of $i_{-2}$ in these equations is based on the assumption that changes in time deposits in period $\mathrm{t}-2$ induced by changes in the market interest rate affect current required reserves. This is a highly questionable assumption (see below). Therefore, it might be more reasonable to use the reduced-form eqaations obtained by letting $\mu=0$. slowly or rapidly depending on whether $\varphi$ is close to one or zero. Furthermore, under the general condition that $\varphi<0$, the system will oscillate toward its long-run equilibrium, as indicated by Laufenberg."

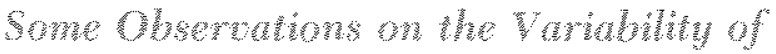

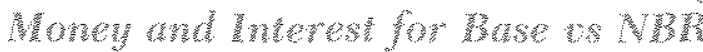

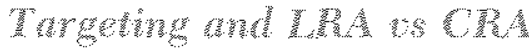

The question naturally arises about the variability of the endogenous variables under alternative operating procedures and under different institutional arrangements. Unfortunately, the model does not lead to conclusive answers to these questions. We begin by dealing with the question of the variability of the money stock under base and NBR targeting.

The error terms for the money stock under base and NBR targeting are, respectively:

$$
\begin{aligned}
& \frac{\lambda(\mathrm{r}(\mathrm{l}+\tau)+\mathrm{e}-\mathrm{I})}{(1+\mathrm{k}) \Delta_{0}} \mathrm{u}_{\mathrm{ct}}-\frac{\lambda}{\Delta_{0}}\left(\mathrm{ru}_{\mathrm{\tau t}}+\mathrm{u}_{\mathrm{ct}}\right) \\
& +\frac{(1+k)(r \mu+\delta+\rho)-\rho(r(1+\rho)+e+k)}{(1+k) \Delta_{0}} u_{1 n t} \\
& \text { and } \frac{\lambda(\mathbf{r}(1+\tau)+e)}{(1+k) \Delta_{1}} u_{t:}+\frac{\lambda}{\Delta_{1}}\left(\mathbf{u}_{b t}-r_{t \xi}-\mathbf{z}_{e t}\right\} \\
& +\frac{(1+k)(r \mu+\hat{o}+\alpha)-\rho(\mathrm{r}(1++)+e)}{(1+k) \Delta_{1}} u_{m t}
\end{aligned}
$$

If we denote the variance of money under base and NBR targeting by $\mathrm{V}\left(\mathrm{M}_{\mathrm{r}}^{\mathrm{B}}\right)$ and $\mathrm{V}\left(\mathrm{M}_{\mathrm{r}}^{\mathrm{N}}\right)$, respectively, and if we assume the individual error terms are independent of each other and through time, we get

$$
\begin{aligned}
& V\left(\mathrm{M}_{\mathrm{t}}^{\mathrm{B}}\right)=\left[\frac{\lambda(\mathrm{r}(\mathrm{l}+\tau)+\mathrm{e}-1)}{(1+\mathrm{k}) \Delta_{0}}\right]^{2} \sigma_{v}^{2} \\
& +\left[-\frac{\lambda}{\Delta_{0}}\right]^{2}\left(\mathrm{r}^{2} \boldsymbol{\sigma}_{\mathrm{\tau}}^{2}+\sigma_{\mathrm{e}}^{2}\right) \\
& +\left[\frac{(1+k)(r \mu+\delta+\rho)-p\left(r\left(1+\frac{1}{2} \tau\right)+e^{+}-k\right)}{(1+k) \Delta_{9}}\right]^{2} \sigma_{1 \mathrm{~s}}^{2}
\end{aligned}
$$

and

$V\left(M_{f}^{N}\right)=\left[\frac{\lambda(r(1+\tau)+e)}{\left(1+s_{1}\right) \Delta_{1}}\right]^{2} \sigma_{c}^{2}+\left[\frac{\lambda}{\Delta_{1}}\right]^{2}\left(\sigma_{b}^{2}+r^{2} \sigma_{7}^{2}+\theta_{e}^{2}\right)$

\footnotetext{
${ }^{3}$ See Daniel E. Lanfenberg, "Contemporaneous Versels Lagged Reserve Acounting," Journal of Money, Credit and Banking (May 1976), pp. 239-45.
} 


$$
+\left[\frac{(1+k)(r \mu+\delta+\alpha)-\rho(r(1+\tau)+e)}{(1+k) \Delta_{1}}\right]^{2} \sigma_{\mathrm{ta}}^{2}
$$

A number of interesting observations can be made from the above. First, random shocks to currency, $u_{c t}$, move money in opposite directions under base and NBR targeting if $0<r(1+\tau)+e<1$. Under this condition, a random increase in currency will reduce the money stock under base targeting and increase it under NBR targeting. Furthermore, the magnitude of this shock on the money stock will be larger under base targeting. This can be seen by noting that the absolute value of the coefficient on $u_{c t}$ under base targeting will be larger than under NBR targeting if $r(1+\tau)+e<1 / 2$ and if $\Delta_{0}\left|<\Delta_{1}\right|$ Thus, the variance of money associ ated with random changes in currency will be larger under base targeting.

The variance of money associated with other supplyside shocks will be smaller under NBR targeting if $\left|\Delta_{0}\right|<\left|\Delta_{1}\right|$. This condition requires $(\lambda k+\rho) /(1+k)>$ $\alpha$. Standard estimates of these parameters suggest that this condition will hold. Thus, supply-side shocks will have a greater impact on the money supply under base targeting. Note, however, that if the discotnt rate were tied so that, effectively, $\alpha=0$, the above condition would not hold, and more stable monetary control could be achieved through base targeting.

Second, the variance of money associated with random shifts in money demand can be seen to be larger under NBR targeting if the money supply schedule is flatter. This can be seen by denoting the slopes of the money supply under base and NBR targeting by $1 / \downarrow_{\mathrm{B}}$ and $1 / \psi_{\mathrm{N}}$, respectively, where

$\psi_{13}=\frac{\rho(r(1+\tau)+e+k)-(1+k)(r \mu+\delta+\rho)}{r(1+\tau)+e+k}$

and

$u_{\mathrm{N}}=\frac{\rho(\mathrm{r}(1+\mathrm{T})+\mathrm{e})-(1+\mathrm{k})(\mathrm{r} \mu+\delta+\alpha)}{\mathrm{r}(1+\tau)+e}$

Now note that the money supply schedule is flatter under NBR targeting if $\psi_{\mathrm{B}}<\psi_{\mathrm{N}}$, which, in turn, requires $\frac{\rho(r(1+\tau)+e)-k(r \mu+\delta)}{r(1+\tau)+e+k}>\alpha$. We now note that the coefficients on the $\sigma_{m}^{2}$ term of the above expressions are simply $\left[\frac{\psi_{\bar{i}}}{-\lambda+\psi_{i}}\right]^{2}, i=B$ and $N$. It is casy to see that the general conclusion about the sensitivity of the money stock to random changes in the demand for money hold if $\psi_{\mathrm{B}}<\mathrm{U}_{\mathrm{N}}$
Third, random shocks in depository institutions' borrowing have no impact on money under base targeting, but they do under NBR targeting. If the variance of these shocks are larger-relative to the variances of currency, excess reserves and time deposits-the net eflect of supply-side shocks from all sources could be larger under NBR targeting. Thus, no general conclusion about the variability of money under base and NBR targeting can be reached. (The outcome depends on the magnitudes of $\sigma_{6}^{2}, \sigma_{*}^{2}$, and $\sigma_{0}^{2}$ relative to $\sigma_{\mathrm{m}}^{2}$ and on the magnitude of $\sigma_{\mathrm{b}}$.

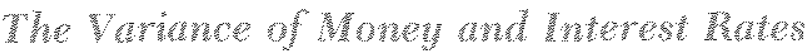

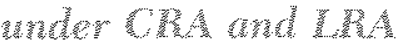

Now consider the variance of money and interest rates under CRA, LRA and the Board's proposal for CRA. Only the case of base targeting will be dealt with; however, the results hold for NBR targeting as well. For simplicity, assume that the individual structural errors are independent (relaxing this assumption makes determining the relative variability under CRA and LRA more difficult). It is easy to show that the error terms for the equilibrium money stock under CRA and LRA, respectively, are

$$
\begin{gathered}
\frac{\lambda(\mathrm{r}(1+\tau)+e-1)}{(1+\mathrm{k}) \Delta_{0}} \mathrm{u}_{\mathrm{ct}}-\frac{\lambda}{\Delta_{0}}\left(\mathrm{ru}_{\mathrm{rt}}+\mathrm{u}_{\mathrm{et}}\right) \\
+\frac{(1+\mathrm{k})(\mathrm{r} \mu+\delta+\rho)-\rho(\mathrm{r}(1+\tau)+e+\mathrm{k})}{(1+\mathrm{k}) \Delta_{0}} \mathrm{u}_{\mathrm{m}, \mathrm{t}}
\end{gathered}
$$

and

$$
\begin{aligned}
& \frac{\lambda(e-1)}{(1+k) \Delta_{2}} u_{p t}-\frac{\lambda}{\Delta_{2}}\left(u_{m i}+u_{e t}\right) \\
& +\frac{(1+k)(\delta+p)-p(e+k)}{(1+k) \Delta_{2}} u_{m i}
\end{aligned}
$$

If we let $V\left(\mathrm{M}_{1}^{\circ}\right)$ and $\mathrm{V}\left(\mathrm{M}^{\mathrm{Q}}\right)$ denote the variance of money under CRA and LRA, respectively, we obtain

$$
\begin{aligned}
& V\left(M_{i}^{i}\right)=\left[\frac{\lambda\left(r\left(1+\frac{1}{2}+\right)+e-1\right)}{(1+k) \Delta_{0}}\right]^{2} \sigma_{c}^{2} \\
& +\left[\frac{\lambda}{\Delta_{0}}\right]^{2}\left\langle\mathrm{r}^{2} \sigma_{*}^{2}+\sigma_{k}^{2}\right) \\
& +\left[\frac{(1+k)(r k+\delta+\rho)-\rho(r(1+\tau)+e+k)}{(1+k) \Delta_{0}}\right]^{2} \sigma_{m}^{2}
\end{aligned}
$$

and

$V\left(M_{1}^{q}\right)=\left[\frac{\lambda(e-1)}{(1+k) \Delta_{2}}\right]^{2} \sigma_{e}^{2}+\left[\frac{\lambda}{\Delta_{2}}\right]^{2}\left(\mathrm{r}^{2} \sigma_{\tau}^{2}+\sigma_{e}^{2}\right)$ 


$$
+\left[\frac{(1+k)(\delta+\rho)-p(e+k)}{(1+k) \Delta_{2}}\right]^{2} \sigma_{\mathrm{m}}^{2}
$$

It is easy to see that $\mathrm{V}\left(\mathrm{M}_{\mathrm{C}}\right)<\mathrm{V}\left(\mathrm{M}_{\mathrm{t}}^{\mathrm{i}}\right)$. This can be done by noting that $(\mathrm{r}(\mathrm{l}+\tau)+\mathrm{e}-1)^{2}<(\mathrm{e}-1)^{2}$ for $(\mathrm{r}(1+\tau)+\mathrm{e})<1$, and that $\left(\Delta_{0}\right)^{2}>\left(\Delta_{2}\right)^{2}$. Furthernore, it is clear from our previous analysis that the coefficient on the variance of money will be smaller under CRA if the money supply schedule is flatter under LRA than under CRA."

Note that this conclusion depends on including $u_{x \neq-2}$ in the error term for the equilibrium money stock under LRA. If the Federal Reserve could identify random changes in time deposits and make corresponding compensatory changes in the reserve aggregate, changes in $u_{T t-2}$ would not affect the current money stock. Thus, the variance of money under LRA would be smaller than indicated above by

$$
\left[\frac{\lambda_{r}}{\Delta_{0}}\right]^{2} \sigma_{\tau}^{2} .
$$

In this instance, it is impossible to say whether $\mathrm{V}\left(\mathrm{M}_{\mathrm{t}}\right)$ is larger or smaller than $\mathbf{V}\left(\mathbf{M}_{t}\right)$. Furthermore, the structure of other equations might change with a change in reserve accounting. ${ }^{\circ}$

If we denote the variance of money under the Federal Reserve's proposal as $\mathrm{V}\left(\mathrm{M}_{\mathrm{b}}^{\mathrm{b}}\right)$, it is easily shown that

$$
\begin{aligned}
& V\left(M_{1}\right)=\left[\frac{\lambda(r+c-1)}{(1+k)\left(\Delta_{3}\right)}\right]^{2} \sigma_{c}^{2}+\left[\frac{\lambda}{\Delta_{3}}\right]^{2}\left(\sigma_{0}^{2} \sigma_{i}^{2}+\sigma_{k}^{2}\right) \\
& +\left[\frac{\left.(1+k)(\delta+\rho)-p^{(2}+e+k\right)}{(1+k) \Delta_{3}}\right]^{2} \pi_{n=2}^{2}
\end{aligned}
$$

where

$$
\Delta_{3}=\frac{(\lambda-p)(r+k+e)}{1+k}+(\delta+p)
$$

This condition is simply that

$$
\mu>\frac{(1+\tau)(\delta+p)}{(e+k)}
$$

While the general conclusion that $V(M)$ need not be less than $V\left(M_{2}^{\mathbb{Z}}\right)$ will remain valia under altemative spectications of this model, this specific result may change. For example, this expression would change if there were different reserve ratios on time and transactions deposits and if excess reserve holdings depended on both time and transactions leposits.

"This need not be the case, however. If there were sudden changes in reserves due to deposit shifts $\Delta \mathrm{D}$, the anount of natket oper:ations necessary to restome a bank's reserve position would be $(1-r)$ $\triangle D$ under CRA and $\triangle D$ under LRA. This need for greater market activity under LRA could offset any effect on excess reserves associated with greater certainty of required reserves.
Clearly $\left(\Delta_{3}\right)^{2}>\left(\Delta_{2}\right)^{2}$. Furthermore, $[(1+k)(\delta+\rho)-\rho(r+e+k)]^{2}<[(1+k)(\delta+\rho)-\rho(e+k)]^{2}$. Thus, $V\left(M_{t}^{b}\right)<V\left(M_{t}^{k}\right)$. The move from the current system of LRA to the Board's proposed system of CRA should reduce the variance of the money stock. This conclusion is true whether $\sigma_{\tau}^{2}$ is included or excluded from these expressions.

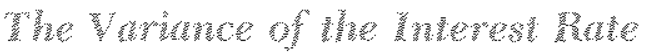

Denote the variances of the interest rate with respect to CRA, LRA and the Board's proposal as $V\left(i_{t}^{c}\right)$, $V\left(i_{t}^{k}\right)$ and $V\left(i_{t}^{b}\right)$, respectively. Then,

$$
\begin{aligned}
& V(6)=\left[\frac{(r(1+\tau)+e+k-1)}{(1+k) \Delta_{8}}\right]^{2} \sigma_{c}^{2} \\
& +\left[\frac{-1}{(1+k) \Delta_{0}}\right]^{2}\left(r^{2} \sigma_{\tau}^{2}+v_{0}^{2}\right) \\
& +\left[\frac{-[\mathrm{r}(\mathrm{l}+\mathrm{t})+\mathrm{e}+\mathrm{k}]}{\left(1+\mathrm{k} \Delta_{0}\right.}\right]^{2} \\
& V\left(\sigma_{t}^{k}\right)=\left[\frac{e+k-1}{(1+k) \Delta_{2}}\right]^{2} \sigma_{c}^{2}+\left[\frac{-1}{(1+k) \Delta_{2}}\right]^{2}\left(\sigma^{2} \sigma_{T}^{2}+\sigma_{c}^{2}\right) \\
& +\left[\frac{-(e+k)}{(1+k) \Delta_{2}}\right]^{2} \theta_{n}^{2} \\
& V\left(h_{3}\right)=\left[\frac{r+e-1}{(1+k) \Delta_{3}}\right]^{2} \sigma_{c}^{2}+\left[\frac{-1}{(1+k) \Delta_{3}}\right]^{2}\left(r^{2} \sigma_{7}^{2}+\sigma_{r}^{2}\right) \\
& +\left[\frac{-(r+e+k)}{(1+k) \Delta_{3}}\right]^{2} \sigma_{\mathrm{v}}^{2} .
\end{aligned}
$$

As with the comparison of the variances of money, a comparison of $\mathrm{V}\left(\mathrm{i}_{\mathrm{t}}^{\mathrm{c}}\right)$ and $\mathrm{V}\left(\mathrm{i}_{\mathrm{t}}\right)$ depends on whether the term

$\left[\frac{-r}{(1+k) \Delta_{i}}\right]^{2} \sigma_{*}^{2}$

is included or excluded under LRA. With respect to the variance of interest rates, however, there is an additional complication; it is not immediately clear whether

$\left[\frac{-(\mathrm{r}(\mathrm{l}+\tau)+\mathrm{e}+\mathrm{k})}{(\mathrm{I}+\mathrm{k}) \Delta_{0}}\right]^{2} \geq\left[\frac{-(\mathrm{e}+\mathrm{k})}{(1+\mathrm{k}) \Delta_{2}}\right]^{2}$

A little algebra shows that the condition requires

$\frac{(1+\tau)(\delta+p)}{(e+k)} \leq \mu$

This is the condition required for the slope of the money supply schedule to be steeper or flatter under CRA than under LRA. This adds another element of 
ambiguity to the determination of the relative variance of interest rates under CRA and LRA.

A similar problem makes the determination of the relative magnitudes of $V\left(i_{t}^{b}\right)$ and $V\left(i_{t}^{2}\right)$ ambiguous. This is seen by noting that $V\left(i_{t}^{b}\right)<V\left(\begin{array}{l}l_{1} \\ t_{t}\end{array}\right)$ if

$\left[\frac{-(\mathrm{r}+\mathrm{e}+\mathrm{k})}{(1+\mathrm{k}) \Delta_{3}}\right]^{2} \boldsymbol{\sigma}_{\mathrm{ra}}^{2}<\left[\frac{-(\mathrm{e}+\mathrm{k})}{(1+\mathrm{k}) \Delta_{2}}\right]^{2} \boldsymbol{\sigma}_{\mathrm{r}}^{2}$

Following the same procedure as above, it can be shown that this condition will hold only if

$$
r(\delta+\rho)>0 \text {. }
$$

Given the restrictions on the signs of these parameters, this cannot hold. Therefore, the last term in the expression for $V\left(i_{t}^{b}\right)$ is strictly larger than the last term in the expression for $V\left(i_{t}^{*}\right)$. Thus, it is indeterminate whether the Board's proposal for CRA will increase or reduce the variability of interest rates from the present system.

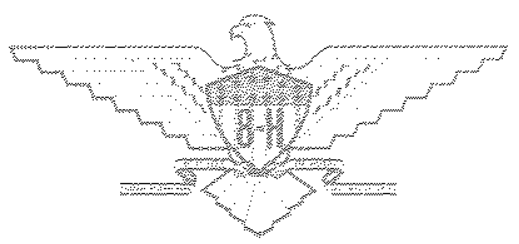

